Edited by Robert A. Weinstein, MD

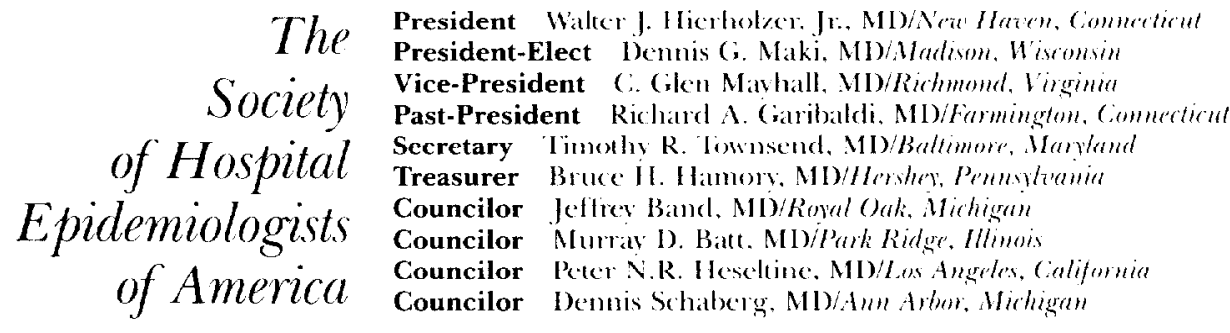

New Infection Control Standards

Revised infection control standards (see February, 1989 Newsletter) have been adopted by the Joint Commission's Board of Commissioners for inclusion in the Joint Commission on Accreditation of Healthcare Organizations 1990 Accreditation Manual for Hospitals.

The Joint Commission is now developing "scoring guidelines" for the revised chapter. To minimize any possible or perceived inconsistency in surveyors'judgments about hospital compliance with Joint Commission standards, the Joint Commission has been developing and applying "scoring guidelines" for the past three years. These guidelines are meant to state some ways in which standards can be met, including the most common and optional ways to meet a standard.

Because the revised infection control standard is much less specific than previous versions, the new scoring guidelines for infection control probably will include a fuller description of the option(s) that would be considered as complying with the standards. An important goal of the revised guidelines is to provide guidance for less experienced infection control programs. It is hoped also that more explicit scoring guidelines will further facilitate consistency in surveyor judgment about compliance.
The draft of the new scoring guidelines presently is being reviewed by the extramural infection control expert panel that reviewed the drafts of the new standards. The panel includes repre sentation from SHEA.

\section{SHEA Luncheon Reminder}

Reminder! The Annual SHEA Luncheon and Business meeting will be Monday, September 18, 1989 from noon to 1:30 p.m. in Houston, Texas, during the Interscience Conference on Antimicrobial Agents and Chemotherapy (ICAAC). The luncheon meeting will be in the Ballroom of the Four Seasons Hotel (1300 Lamar Street), a short walk from the ICAAC Convention Center. Dr. W. Paul Clezen will speak on influenza in the hospital.

\section{J ob Market}

The Hospital Infections Program (HIP), Centers for Disease Control (CDC), is seeking an epidemiologist to lead the Nosocomial Infections Surveillance Activity. The applicant should have an MD degree, be board certified or board eligible in infectious diseases and have training and experience in epidemiology. Experience in mechanisms and epidemiology of antimicrobial resistance and in microcomputer and mainframe computer use is desirable.

The Nosocomial Infections Surveillance Activity will be responsible for the National Nosocomial Infections Surveillance System (NNIS). NNIS is the only national surveillance system for nosocomial infections. Data are collected and provided to CDC by 90 NNIS member hospitals using microcomputer software (NN IS IDEAS) developed by HIP.

'The candidate selected for this position will lead a team of professionals to establish priorities for analysis of existing NNIS data, to develop new surveillance components to address specific areas of inquiry and to develop methodologies to evaluate the effectiveness of NNIS as a prevention tool. Additional responsibilities will include developing strategies to monitor antibiotic resistance among nosocomial pathogens and ways to apply newly developed or acquired laboratory research techniques on antimicrobial resistance to epidemiologic studies.

This assignment is available immediately. Interested persons are encouraged to send a curriculum vitae with names of three references to William V. Nelson, Personnel Management Office, Centers for Disease Control (D01), Atlanta, GA 30333; Telephone (404) 639-3271. 